\title{
Performance Study of 1 Tbits/s WDM Coherent Optical OFDM System
}

\author{
Khaled Alatawi, Fahad Almasoudi, Mohammad A. Matin \\ Department of Electrical and Computer Engineering, University of Denver, Denver, USA \\ Email:khaledbs@hotmail.com
}

Received June 5, 2013; revised July 7, 2013; accepted August 3, 2013

Copyright (C) 2013 Khaled Alatawi et al. This is an open access article distributed under the Creative Commons Attribution License, which permits unrestricted use, distribution, and reproduction in any medium, provided the original work is properly cited.

\begin{abstract}
This paper investigates the architecture of Tbits/s Wavelength Division Multiplexing (WDM) system by using a Coherent Optical Orthogonal Frequency Division Multiplexing (CO-OFDM) with 4-QAM for long haul transmissions of $1800 \mathrm{Km}$ SM. A simulation of $20 \mathrm{WDM}$ channels spaced at $50 \mathrm{GHz}$, and 20 OFDM signals each with 50 Gbits/s bitrate to produce data rate of $1 \mathrm{Tbits} / \mathrm{s}$ is built. The system performance is studied by observing the constellation diagram of the signal and the relationship of BER and OSNR with regard to transmission distance. The results show that the BER increases as the transmission distance increases. Also, as the transmission distance increases, the OSNR needs to be increased to maintain BER in less than $10^{-3}$.
\end{abstract}

Keywords: WDM; QAM; CO-OFDM; BER; OSNR

\section{Introduction}

The demand for high data rate and high capacity in the optical communications field has motivated researchers to try different modulation formats that can support this demand. Among this was Coherent Optical OFDM which got special attention due to its tolerance to Chromatic Dispersion (CD) and Polarization Mode Dispersion (PMD) [1]. In addition, CO-OFDM has a great potential when it comes to receive sensitivity and spectral efficiency. Tbits/s transmission rate is available through the WDM (Wavelength Division Multiplexing) transmission system; but, this system has a low spectral efficiency due to wavelength spacing [2-4]. However, integrating WDM with CO-OFDM will produce a system with high spectral efficiency; better tolerance to PMD and CD; and, significantly high data rate. Because of the great potential of $\mathrm{CO}-\mathrm{OFDM}$, it is considered the solution to upgrade todays' $10 \mathrm{Gbits} / \mathrm{s}$ transmission rate to over $100 \mathrm{Gbits} / \mathrm{s}$ [5-8].

This paper demonstrates the architecture of Tbits/s WDM-CO-OFDM system. In this experiment, we studied a WDM system by using CO-OFDM with 4-QAM (Quadrature Amplitude Modulation). 20 WDM channels are used with a $50 \mathrm{GHz}$ wavelength space and 20 OFDM signals, each with $50 \mathrm{Gbits} / \mathrm{s}$ to produce a net data rate of 1 Tbits/s. To study the performance of the system, we focused on the constellation diagram of the system and the relationship of the BER (Bit Error Rate) and the OSNR (Optical Signal to Noise Ratio) with regard to transmission distance.

\section{System Design}

The WDM CO-OFDM system is simulated and studied using an OptiSystem V.11 simulation tool. The simulation diagram is shown in Figure 1. The design consists of three main parts: CO-OFDM Tx (Transmitter), optical fiber link and CO-OFDM Rx (Receiver). In the WDM system, 20 channels with $50 \mathrm{GHz}$ channel spacing are used to support 20 OFDM bands, each with a 50 Gbits/s bitrate to reach $1 \mathrm{Tbits} / \mathrm{s}$ data rate. Important simulation parameters are shown in Table 1.

\subsection{CO-OFDM Tx Design}

Figure 2 shows the CO-OFDM transmitter design; the bit stream is generated by a PRBS generator and mapped by a4-QAM encoder. The resulting signal is modulated by an

Table 1. Simulation global parameters.

\begin{tabular}{cc}
\hline \multicolumn{2}{c}{ Global Parameters } \\
\hline Sequence length & 16,384 Bits \\
Samples per bit & 8 \\
Number of samples & 131,072 \\
\hline
\end{tabular}




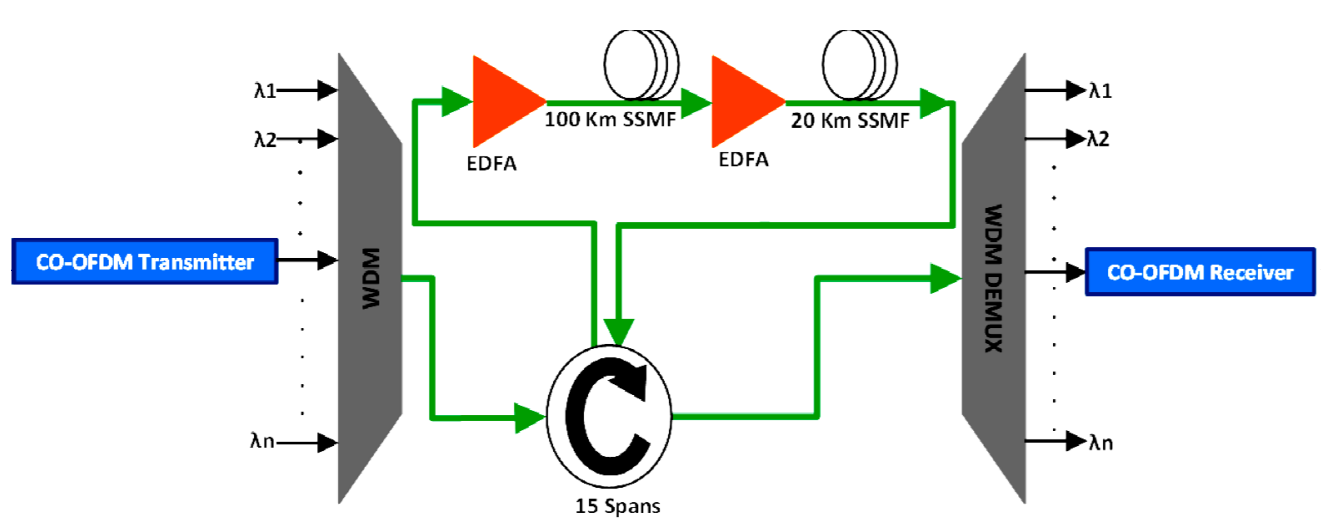

Figure 1. WDM CO-OFDM system design.

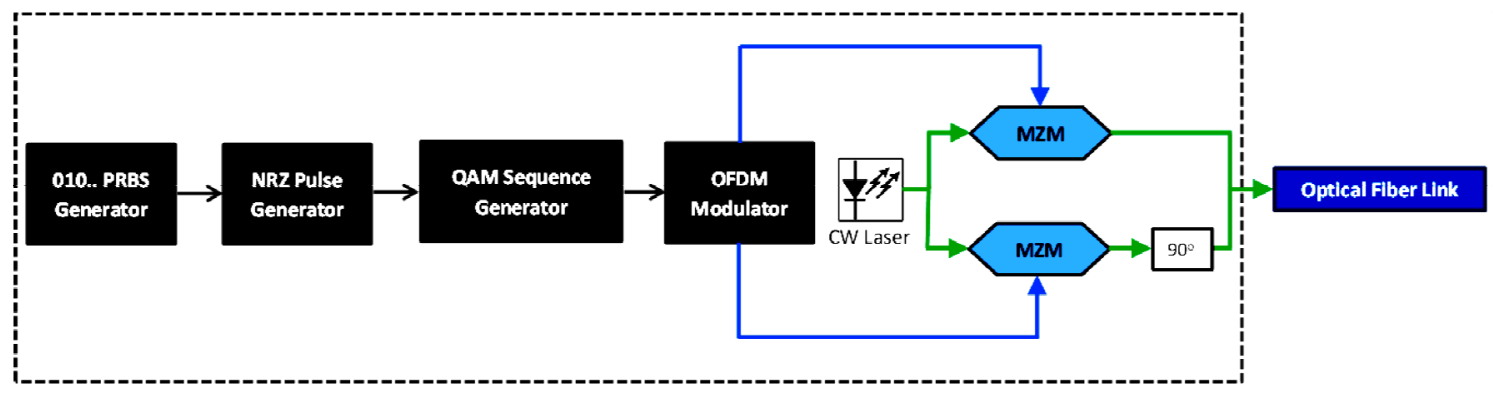

Figure 2. CO-OFDM transmitter design.

OFDM modulator; the parameters are shown in Table 2. After that, the resulting electrical signal is modulated to the optical signal using a pair of Mach-Zehnder modulators (MZM). Figure 3 shows the in-phase and quadrature parts of the OFDM signal, where Figure 4 shows the signal after the two MZMs which will be fed to the optical link. The laser source has a line width of $0.15 \mathrm{MHz}$ and launch power of $-5 \mathrm{dBm}[9,10]$.

\subsection{Optical Fiber Link}

The optical link consists of 15 spans of $100 \mathrm{Km} \mathrm{SMF}$, with a dispersion coefficient of $16 \mathrm{ps} / \mathrm{nm} / \mathrm{Km}$, nonlinearity coefficient of $2.6 \times 10^{-20}$; and, attenuation of 0.2 $\mathrm{dB} / \mathrm{Km}$. SMF parameters are shown in Table 3. Fiber dispersion is compensated by the Dispersion Compensation Fiber (DCF) of $20 \mathrm{Km}$ with a $-80 \mathrm{ps} / \mathrm{nm} / \mathrm{Km}$ coefficient in each span; DCF parameters are shown in Table 4. The attenuation of SMF and DCF are balanced by optical amplifiers with $4 \mathrm{~dB}$ noise figure in each span.

\subsection{CO-OFDM Rx Design}

Figure 5 shows the CO-OFDM receiver design; to recover the I/Q component of the OFDM signal, two pairs of balanced PIN photodetectors and LO (Local Oscillator) lasers are used. The balanced detectors perform the I/Q optical to electrical detection and help perform the noise cancellation. Electrical amplifiers are used to adjust the signal intensity $[11,12]$. After the balanced detectors the
Table 2. OFDM parameters.

\begin{tabular}{cc}
\multicolumn{2}{c}{ OFDM Modulator } \\
\hline Number of subcarrier & 512 \\
IFFT & 1024 \\
guard interval & $1 / 8$ \\
\hline
\end{tabular}

Table 3. SMF parameters.

\begin{tabular}{cc}
\hline \multicolumn{2}{c}{ SMF } \\
\hline Dispersion & $16 \mathrm{ps} / \mathrm{nm} / \mathrm{km}$ \\
Dispersion Slope & $0.08 \mathrm{ps} / \mathrm{nm}^{2} / \mathrm{km}$ \\
PMD Coefficient & $0.2 \mathrm{ps} / \mathrm{km}$ \\
Effective area & $80 \mathrm{um}^{2}$ \\
Nonlinearity Coefficient & $2.6 \times 10^{-20}$ \\
Attenuation & $0.2 \mathrm{~dB} / \mathrm{km}$ \\
\hline
\end{tabular}

Table 4. DCF parameters.

\begin{tabular}{cc}
\hline \multicolumn{2}{c}{ DCF } \\
\hline Dispersion & $-80 \mathrm{ps} / \mathrm{nm} / \mathrm{km}$ \\
Dispersion Slope & $-0.45 \mathrm{ps} / \mathrm{nm}^{2} / \mathrm{km}$ \\
PMD Coefficient & $0.2 \mathrm{ps} / \mathrm{km}$ \\
Effective area & $30 \mathrm{um}^{2}$ \\
Nonlinearity Coefficient & $2.6 \times 10-20$ \\
Attenuation & $0.4 \mathrm{~dB} / \mathrm{km}$ \\
\hline
\end{tabular}



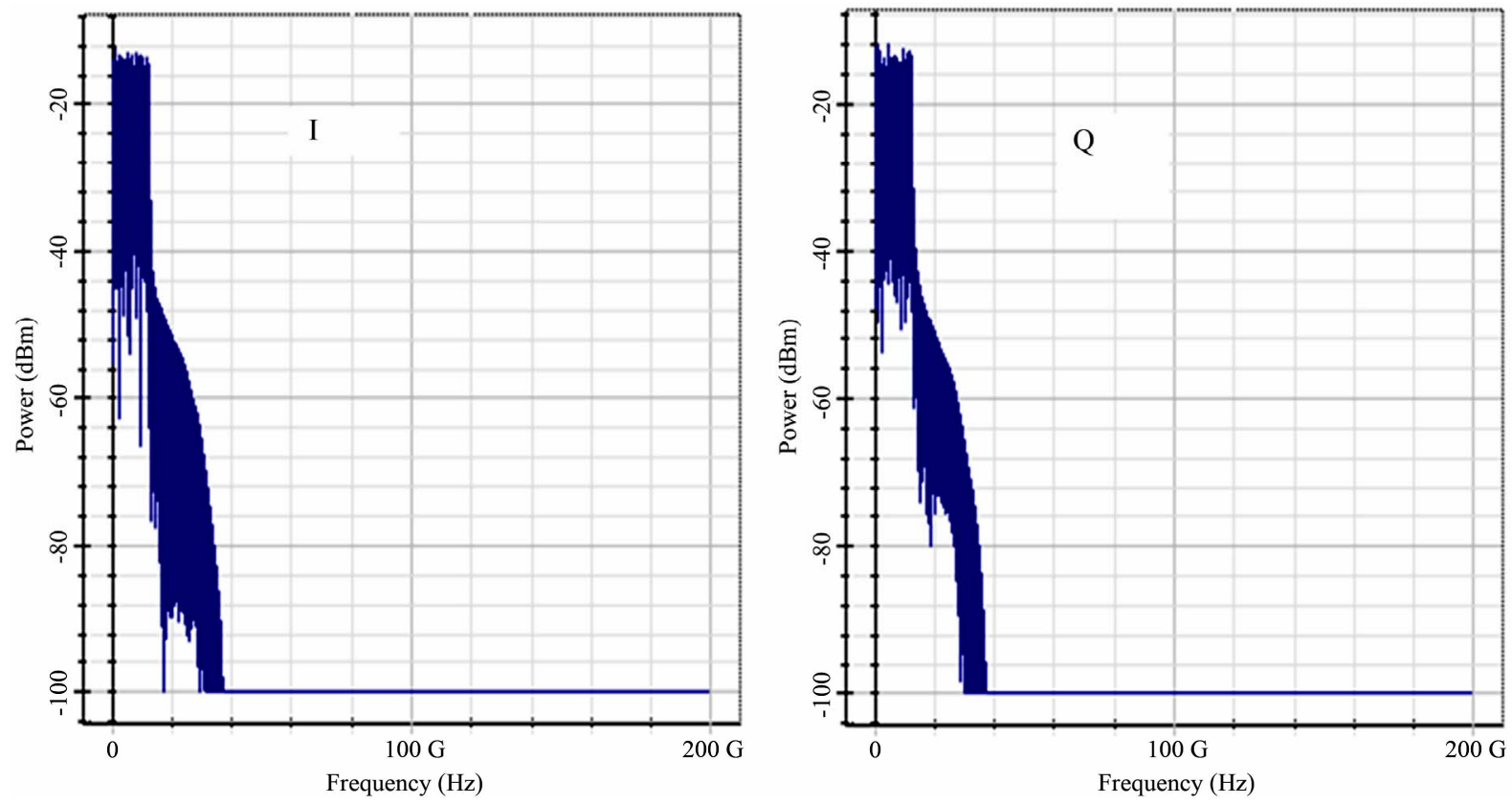

Figure 3. OFDM I/Q spectrum.

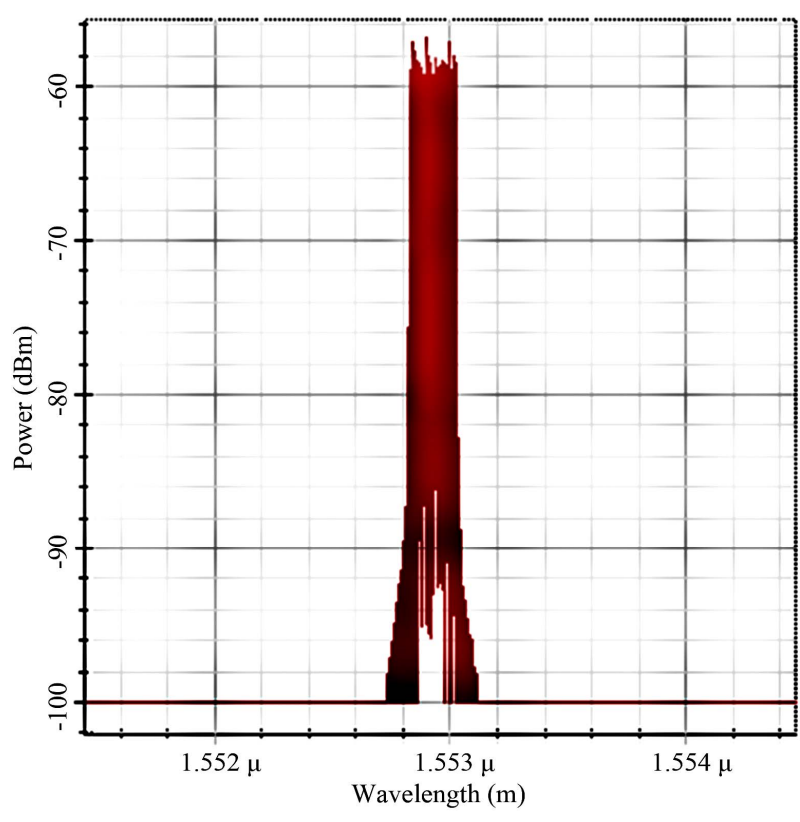

Figure 4. OFDM Signal after the two MZMs.

resulting signal is demodulated using the OFDM demodulator with similar parameters as the OFDM modulator, the guard interval is removed. After that the signal is fed into a 4-QAM decoder, and the BER is calculated at the end [12-16].

\section{Results and Discussion}

Figure 6 shows the RF spectrum of the signal at the transmitter side, where the power of the RF is approximately $-12 \mathrm{dBm}$. Figure 7 shows the RF spectrum at the receiver side after $1800 \mathrm{Km} \mathrm{SMF}$. The power of the RF is decreased to $-22 \mathrm{dBm}$, this decrease in power is because of the increase in fiber length which increases the attenuation.

Figure 8 shows the spectrum 20 OFDM signal after the WDM multiplexer. 20 WDM channels start from 193.05 $\mathrm{THz}$ to $194 \mathrm{THz}$ with $50 \mathrm{GHz}$ of channel space.

The constellation visualizer is an important tool to find if the signal is recovered correctly. The constellation diagram can determine the interference and distortion that happened to the signal. Figure 9 shows the electrical constellation diagram of the 4-QAM digital modulator at the transmitter side.

Figure 10 shows the constellation diagram after 1800 SMF and before using the DCF. It is clear that the chromatic dispersion and the nonlinearity impairments affect the system. So, to improve the signal and remove chromatic dispersion that occurs because of the increase in transmission distance and the data rate, DCF is used. Figure 11 shows the constellation diagram of the signal after using the DCF.

To study the performance of the system for the high data rate, the relationship of the BER and the OSNR with regard to the transmission distance is studied. Figure 12 shows the relationship of the BER and the transmission distance. As can be seen, the BER of short distances is good. However, the BER increases as the transmission distance increases. This happens because of the fiber dispersion which causes the optical pulse to be broadened and produces Intersymbol Interference.

Figure 13 shows the relationship of the BER and the OSNR for different transmission distances. As can be seen 


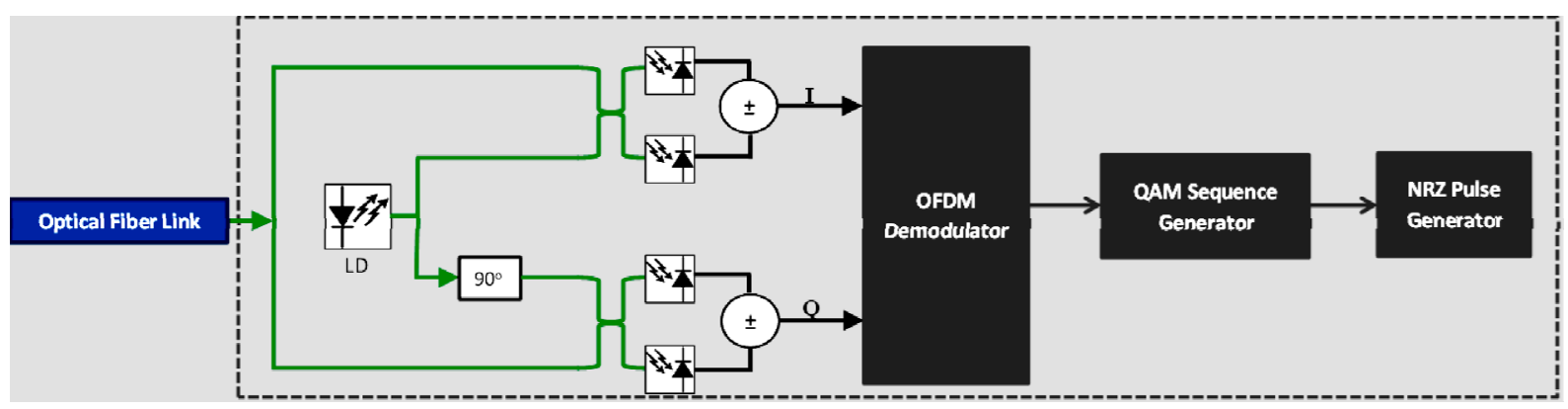

Figure 5. CO-OFDM receiver design.

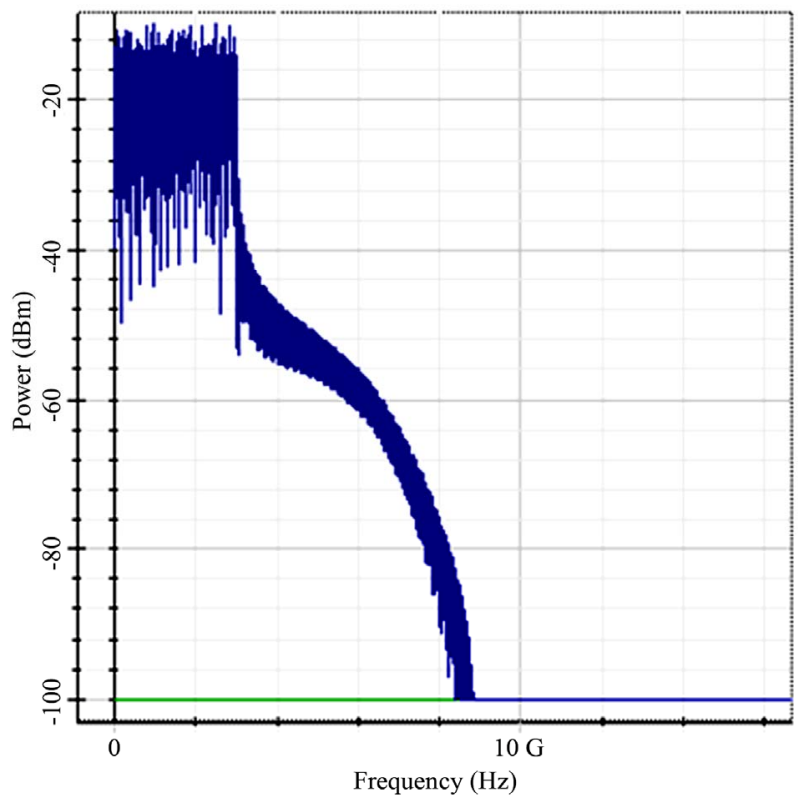

Figure 6. RF spectrum of the signal at the transmitter side.

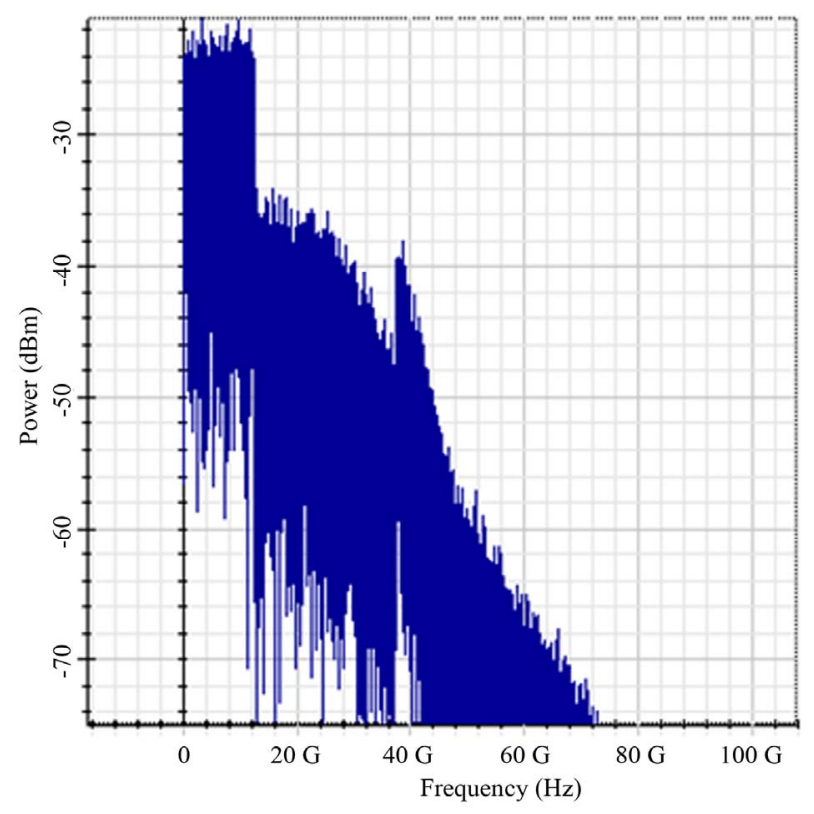

Figure 7. RF spectrum of the signal at the receiver side.

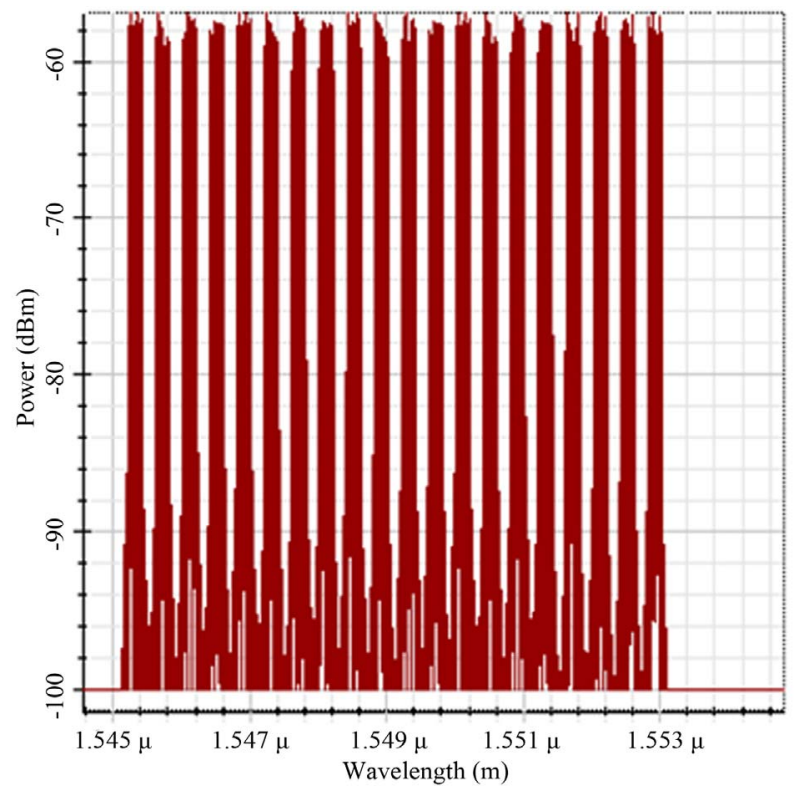

Figure 8. 20 WDM CO-OFDM channels.

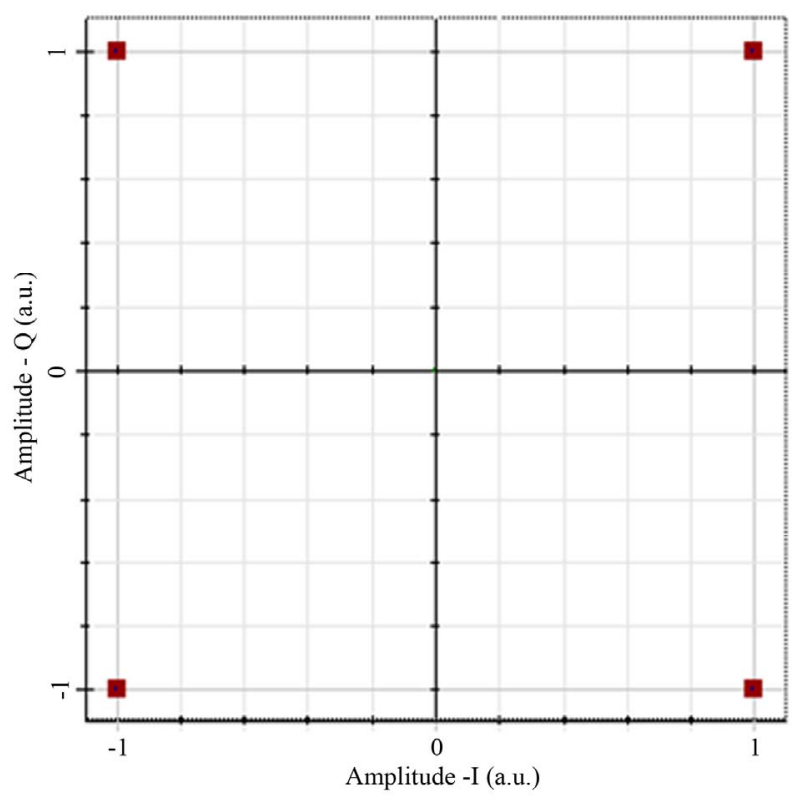

Figure 9. 4-QAM constellation diagram at the transmitter side. 


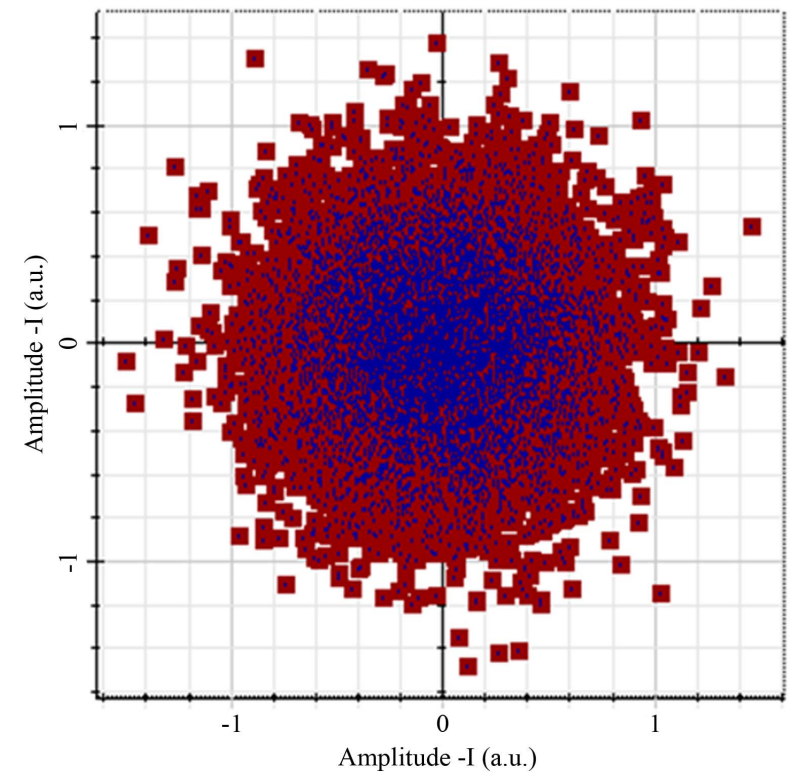

Figure 10. Constellation diagram after $1800 \mathrm{Km}$ before using the DCF.

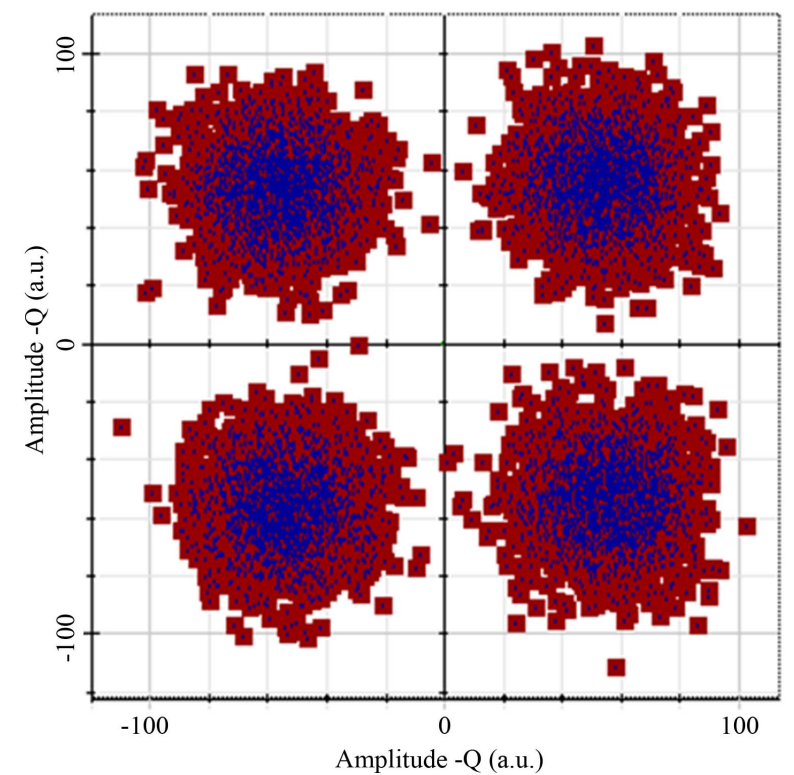

Figure 11. Constellation diagram after $1800 \mathrm{Km}$ after using the DCF.

from the figure, as the transmission distance increases, larger OSNR is required to maintain a BER of less than $10^{-3}$. However, increasing the OSNR will increase the nonlinearity effects in the fiber which will make the system worse.

\section{Conclusion}

In this paper, the architecture of $\mathrm{Tb} / \mathrm{s} \mathrm{WDM}$ systems is studied by using Co-OFDM. The simulation was designed by $20 \mathrm{WDM}$ channels spaced at $50 \mathrm{GHz}$, and $20 \mathrm{OFDM}$ signals, each with $50 \mathrm{Gbits} / \mathrm{s}$ bitrate to produce $1 \mathrm{Tbits} / \mathrm{s}$

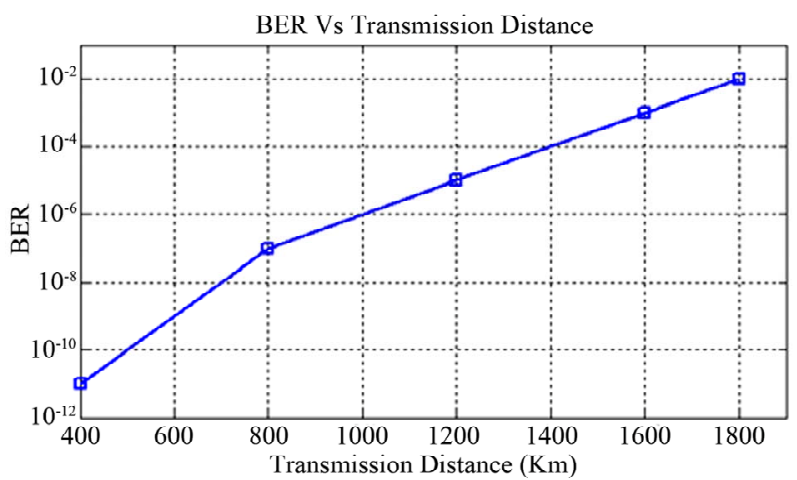

Figure 12. Constellation diagram after $1800 \mathrm{Km}$ after using the DCF.

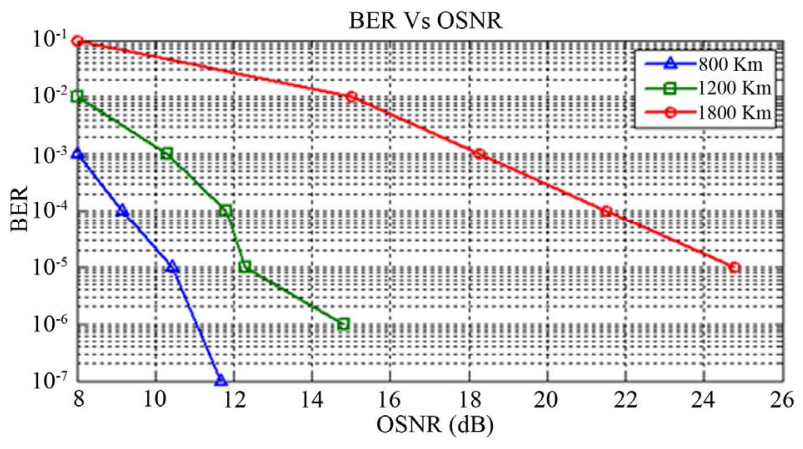

Figure 13. The relationship of BER and OSNR for different transmission distance.

data rate. The proposed system gives clear results to prove it to be reliable. The results show that as the transmission distance increases, the BER increases. Also, when the transmission distance increases, larger OSNR is needed to maintain a BER in less than $10^{-3}$. However, increasing the OSNR will increase the nonlinear effects on the fiber. In the future study of the system, higher order modulations such as: 16-QAM and 32-QAM, will be used to improve the system performance.

\section{REFERENCES}

[1] X. Yi, N. Fontaine, R. Scott and S. Yoo, “Tb/s Coherent Optical OFDM systems Enabled by Optical Frequency Combs," Journal of Lightwave Technology, Vol. 28, No. 14, 2010, pp. 2054-2061. doi:10.1364/OE.16.000841

[2] W. Shieh, H. Bao and Y. Tang, "Coherent Optical OFDM: Theory and Design," Optics Express, Vol. 16, No. 2, 2008, pp. 841-859.

[3] Z. Wang, X. Xie, J. Zhao, Z. Tong and X. Yang, "Performance Analysis of Different Modulation Schemes For Coherent Optical OFDM System," 2010 International Conference on Communications and Mobile Computing (CMC), Shenzhen, 12-14 April 2010, pp. 23-25.

[4] W. Shieh and I. Djordjevic, "OFDM for Optical COMMUNICATIONS,” Academic Press, Waltham, 2009.

[5] I. Djordjevic, L. Xu and T. Wang, "Beyond $100 \mathrm{~Gb} / \mathrm{s}$ Op- 
tical Transmission Based on Polarization Multiplexed Coded-OFDM with Coherent Detection," Journal of Optical Communications and Networking, IEEE/OSA, Vol. 1, No. 1, 2009, pp. 50-56.

[6] B. Liu, X. Xin, L. Zhang and J. Yu," 277.6-Gb/s LDPCCoded CO-OFDM Transmission System with Low PAPR Based on Subcarrier Pre-Filtering Technology," Optics Communications, Vol. 285, No. 24, 2012, pp. 5397-5400. doi:10.1016/j.optcom.2012.07.110

[7] H. Wang, D. Kong, Y. Li, J. Wu and J. Lin, "Performance Evaluation of (D)APSK Modulated Coherent Optical OFDM System," Optical Fiber Technology, Vol. 19, No. 3, 2013, pp. 242-249. doi:10.1016/j.yofte.2013.02.003

[8] W. Shieh, X. Yi and Y. Tang, "Transmission Experiment of Multi-Gigabit Coherent Optical OFDM Systems over 1000 km SSMF Fibre," Electronics Letters, Vol. 43, No. 3, 2007, pp. 183-184. doi:10.1049/el:20073496

[9] Q. Yang, "High-Speed Coherent Optical Orthogonal Frequency-Division Multiplexing Design and Implementation," Ph.D. Dissertation, The University of Melbourne, Melbourne, 2010.

[10] X. Chen, "Theoretical and Experimental Study on High Spectral Efficiency Coherent Optical OFDM Systems," Ph.D. Dissertation, The University of Melbourne, Melbourne, 2012.
[11] J. Pan, "Nonlinear Electrical Compensation for the Coherent Optical OFDM System," M.S. Thesis, Miami University, Oxford, 2010.

[12] F. Almasoudi, K. Alatawi and M. Matin, "Study of OFDM Technique on RoF Passive Optical Network," Optics and Photonics Journal, to be Published.

[13] R. Fyath and M. Al-Qadi, "Investgation of I/Q Imbalance in Coherent Optical OFDM System," World Academy of Science, Engineering and Technology, No. 60, 2011, pp. 1396-1401.

[14] A. Lowery, D. Bangyuan and J. Armstrong, "Performance of Optical OFDM in Ultralong-Haul WDM Lightwave Systems," Journal of Lightwave Technology, Vol. 25, No. 1, 2007, pp. 131-138. doi:10.1109/JLT.2006.888161

[15] Z. Jian and A. Ellis, "Transmission of 4-ASK Optical Fast OFDM with Chromatic Dispersion Compensation," Photonics Technology Letters, IEEE, Vol. 24, No. 1, 2012, pp. 34-36. doi:10.1109/LPT.2011.2171943

[16] Y. Ma, Q. Yang, Y. Tang, S. Chen and W. Shieh, “1-Tb/s Single-Channel Coherent Optical OFDM Transmission over 600-km SSMF Fiber with Subwavelength Bandwidth Access," Optics Express, Vol. 17, No. 11, 2009, pp. 9421-9427. doi:10.1364/OE.17.009421 